\title{
Haynaldia villosa NAM-V1 is linked with the powdery mildew resistance gene Pm21 and contributes to increasing grain protein content in wheat
}

Chuanzhi Zhao ${ }^{1,2}$, Xindi Lv' ${ }^{1}$, Yinghui $\mathrm{Li}^{1}$, Feng $\mathrm{Li}^{1}$, Miaomiao Geng ${ }^{1}$, Yangyang $\mathrm{Mi}^{1}$, Zhongfu $\mathrm{Ni}^{1}$, Xingjun Wang ${ }^{2}$, Chaojie Xie $^{1 *}$ and Qixin Sun ${ }^{1}$

\begin{abstract}
Background: The 6AL/6VS translocation lines, carrying the wheat powdery mildew resistance gene Pm21, are planted on more than 3.4 million hectares. The NAM-A1 gene, located on chromosome 6AS of hexaploid wheat, has been implicated with increased wheat grain protein content (GPC). However, the NAM-A1 gene was removed from the 6AL/6VS translocation lines after the original chromosome 6AS was replaced by chromosome 6VS of Haynaldia villosa. The present study aimed to clone the NAM homologous gene from chromosome 6VS, to analyze the changes of GPC in the 6AL/6VS translocation lines, and to develop related molecular markers for wheat molecular breeding.
\end{abstract}

Results: A new NAM family gene, NAM-V1, was cloned from 6VS of H. villosa (GenBank ACC. no. KR873101). NAM-V1 contained an intact open reading frame (ORF) and putatively encodes a protein of 407 amino acids. Phylogenetic analysis indicated that NAM-V1 was an orthologous gene of NAM-A1,B1, and D1. The determination of GPC in four Pm21 F2 segregation populations demonstrated that the replacement of NAM-A1 by NAM-V1 confers increased GPC in hexaploid wheat. Multiple sequence alignment of NAM-A1, B1, B2, D1, D2, and $V 1$ showed the single nucleotide polymorphism (SNP) sites for each of the NAM genes, allowing us to develop a molecular marker, CauNAM-V1, for the specific detection of NAM-V1 gene. Our results indicate that CauNAM-V1 can be used as a novel DNA marker for NAM-V1, and can also be used for selecting Pm21 in wheat breeding programs. Further, we developed a marker, CauNAM-ABD, for the amplification and simultaneously distinguish among the NAM-A1, NAM-B1, NAM-B2, NAM-D1, and NAM-D2 genes in a single step. CauNAM-ABD enabled us to develop an efficient "one-marker-for-five-genes" procedure for identifying genes and its copy numbers related with grain protein content.

Conclusion: Here, we report the isolation of the NAM-V1 gene of $H$. villosa. This gene contributes to increasing GPC in 6AL/6VS translocation wheat lines. We developed a molecular marker for the specific detection of NAM-V1 and a molecular marker that can be used to simultaneously distinguished among the NAM-A1, NAM-B1, NAM-B2, NAM-D1, and NAM-D2 genes in a single step.

Keywords: Wheat, Haynaldia villosa, NAM gene, Grain protein content, Pm21

\footnotetext{
*Correspondence: xiecj127@126.com

'Key Laboratory of Crop Heterosis and Utilization (MOE) and State Key Laboratory for Agrobiotechnology, Key Laboratory of Crop Genomics and Genetic Improvement (MOA), Beijing Key Laboratory of Crop Genetic Improvement, National Plant Gene Research Centre (Beijing), Department of Plant Genetics \& Breeding, China Agricultural University, Beijing 100193, China Full list of author information is available at the end of the article
} 


\section{Background}

Common wheat (Triticum aestivum) is one of the most important crop in the word, accounting for about $20 \%$ of the world's total calorie consumption and providing about 70 million tons of protein every year. Grain protein concentration (GPC) is an important agronomic trait in wheat. Wheat varieties with high gluten and GPC > $12 \%$ are suitable for making bread. Wheats with low gluten content and GPC $<9 \%$ are suitable for making cookies and cakes [1]. It has been established that the GPC of wheat is a quantitative trait that is affected by environmental conditions [2, 3]. Many wild relatives of wheat, including wild emmer wheat (Triticum turgidum L. var. dicoccoides), have high GPC. In 1991, a complete set of disomic substitution lines were developed by the introgression of each of the chromosomes of wild emmer wheat with high GPC (DIC) into the durum cultivar 'Langdon' (LDN). The substitution line in which the chromosome LDN-6B was completely replaced by DIC-6B, showed the highest protein yield [1, 4]. Later, a quantitative trait locus (QTL) for wheat GPC was mapped onto the short arm of chromosome (6BS) using the recombinant inbred lines DIC and LDN [5], and later mapped within a $2.7 \mathrm{cM}$ region as a single Mendelian locus, $G p c-B 1$ [6]. Uauy et al. (2006) positionally cloned $G p c-B 1$ and established that it is a member of the NAC transcription factor; they renamed it $N A M-B 1$ [7].

The $N A C$ transcript factors are a plant-specific family of transcription factors with a variety of biological functions, including roles in the development of embryos and flowers and responses to biotic and abiotic stress [8-12]. The name $N A C$ is related to the NAM (No Apical Meristem) gene of Petunia, the ATAF1 and ATAF2 (Arabidopsis transcription activation factor) of Arabidopsis, and the CUC2 (cupshaped cotyledon) gene of Arabidopsis.

$N A M-B 1$ in wheat is a typical $N A C$ transcription factor gene; these genes are highly conserved in maize, rice, barley, and other cereal crops [7]. In addition to the NAM-B1 gene on $6 \mathrm{BS}$, its orthologous genes $N A M-A 1$ on $6 \mathrm{AS}$ and $N A M-D 1$ on $6 \mathrm{DS}$, and its homologous genes $N A M-B 2$ on 2BS and NAM-D2 on 2DS have also been identified. The $N A M$ genes of wheat are associated with increasing wheat grain protein, zinc, and iron content. The function of $N A M-B 1, B 2, A 1, D 1$, and $D 2$ are thought to be largely redundant. The silencing of NAM genes resulted in decreases of $30 \%, 36 \%$ and $38 \%$ for GPC, iron, and zinc, respectively [7]. Recently, NAM orthologous genes have been identified in Hordeum vulgare and Triticum timopheevii Zhuk; these have been shown to have the same function $[1,13,14]$.

Haynaldia villosa ( $2 \mathrm{n}=2 \times=14$, V genome), belonging to the tribe Triticeae, is an annual or perennial diploid plant [15]. As one of the important genetic resources for wheat genetic improvement, $H$. villosa contains many excellent traits, including of resistance to cold, salt, drought, and various wheat diseases, winter hardinesscold, vigorous tillering ability, multi-spikelet morphology, and high grain protein content [16]. Considerable success has been made in transferring beneficial genes from $H$. villosa into wheat via the development and use of substitution and translocation lines. For example, the translocation lines 6AL/6VS carry the powdery mildew resistant gene $P m 21$ and showing strong resistance to most of the powdery mildew isolates. The varieties derived from the 6AL/6VS translocation lines are now planted more than 3.4 million hectares [17]. The Gli-V2 gene for k-type sulfur-rich prolamins was also identified from 6VS of $H$. villosa $[18,19]$. However, to date, no NAM genes have been reported in $H$. villosa. For 6AL/6VS wheat translocation lines, it is unknown about the changes of GPC when the functional $N A M-A 1$ gene on $6 \mathrm{~A}$ chromosome was removed.

In this study, we report the isolation of the NAM-V1 gene from $H$. villosa. We developed a molecular marker, CauNAM-V1, which was specific to NAM-V1 and is linked to the powdery mildew resistance gene $P m 21$. In addition, our results showed that NAM-V1 contributes to increasing GPC in hexaploid wheat. We also developed a marker, CauNAM- $A B D$, which can amplify and simultaneously distinguish among $N A M-A 1, N A M-B 1, N A M-B 2$, $N A M-D 1$, and NAM-D2 in a single step. CauNAM-ABD enabled the development of an efficient "one-marker-forfive-genes" procedure for identifying genes related with grain protein, zinc, and iron content.

\section{Results}

\section{Cloning of the NAM-V1 gene}

The genomic DNA and cDNA of the NAM-V1 gene were amplified from $H$. villosa using two pairs of primers (Fig. 1a). Sequence alignment with known $N A M$ genes cataloged in GenBank confirmed that NAM-V1 is a new NAM homologous gene (NCBI GenBank ACC. no. KR873101). The $N A M-V 1$ gene had $92 \%$ identity with $N A M-A 1,91 \%$ identity with NAM-D1, and $90 \%$ identity with NAM-B1. NAM$V 1$ encodes a NAM superfamily domain protein (Fig. 1b). The full-length of $N A M-V 1$ gene is $1,528 \mathrm{bp}$, and contains three exons and two introns. It is predicted to encodes a protein of 407 amino acids with a molecular weight of 43 KDa (Fig. 1c).

\section{Phylogenetic analysis of NAM proteins}

A neighbor-joining phylogenetic tree was deduced using MEGA 6.0 based the predicted amino acid sequences of NAM-V1 and NAM family proteins of other species (Fig. 2). A total of nineteen proteins were classified into four groups. NAM-V1 belongs to group I, the largest group (10 genes). Group I also includes NAM-A1 encoded by a gene on chromosome $6 \mathrm{~A}$ and NAM-B2 from chromosome $2 \mathrm{~B}$ of durum wheat (T. turgidum var. durum), NAM-B1 from chromosome $6 \mathrm{~B}$ of wild emmer wheat (Triticum. turgidum L. var. dicoccoides), NAM-D1 from chromosome 6D and 


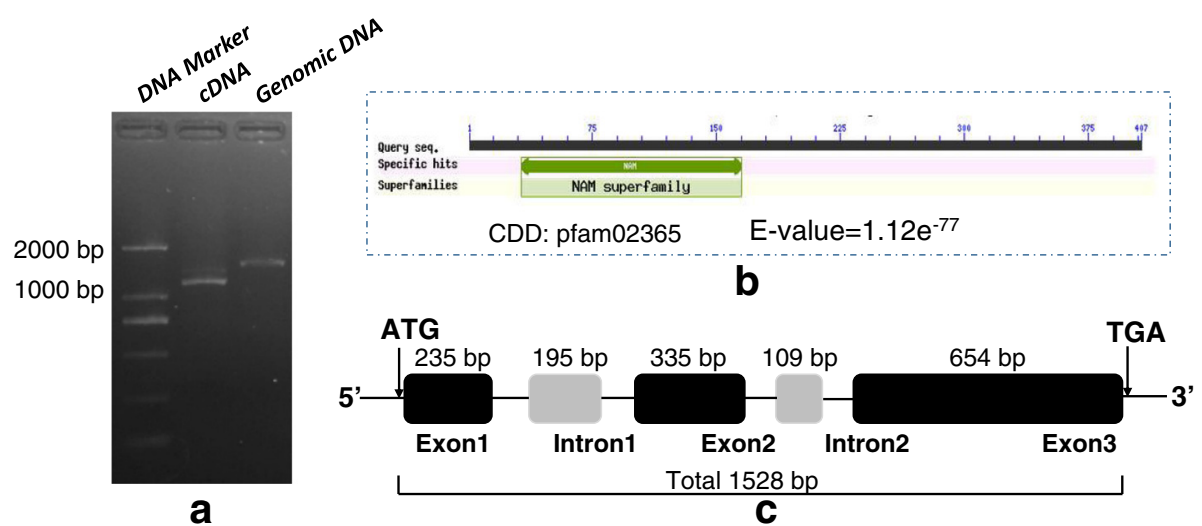

Fig. 1 Cloning and sequence analysis of NAM-V1 gene. a PCR cloning of NAM-V1 gene. b Conserved domain of NAM-V1. c Gene structure of NAM-V1

NAM-D2 from chromosome 2D of Aegilops tauschii, HVNAM1 and HV-NAM2 from the $\mathrm{H}$ genome of Hordeum vulgare, and NAM-G from the G genome of Triticum timopheevii Zhuk. The phylogenetic tree showed that NAM-V1 belonged to the same group with $N A M-A 1, B 1$ and $D 1$, the orthologous genes from the sixth chromosomes of the A, $B$, and D sub genomes, respectively. NAM-B2 and NAMD2, encoded by genes on the second chromosomes of the $\mathrm{B}$ and $\mathrm{D}$ sub genomes, respectively, were also close to

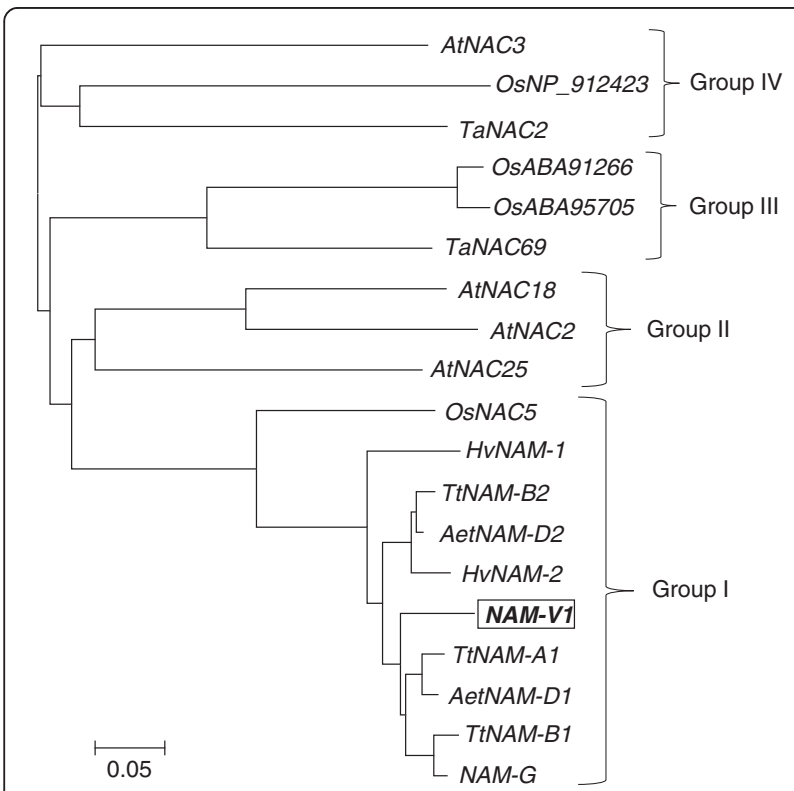

Fig. 2 Phylogenic tree of NAM-V1 and other NAC transcription factors from different species. Species abbreviations: Aegilops tauschii (Aet), T. turgidum (Tt), Hordeum vulgare (Hv), Oryza sativa (Os), Arabidopsis thaliana (At), Triticum timopheevii Zhuk (G). GenBank accession numbers: AtNAC3 (BAB20599), OsNP_912423 (NP_912423), TaNAC2 (AAU08786), OsABA91266 (ABA91266), OsABA95705 (ABA95705), TaNAC69 (AAY44098), AtNAC18 (NP_175696), AtNAC2 (NP_188170), AtNAC25 (NP_564771), OsNAC5 (NP_911241), HvNAM-1 (DQ869678), TtNAM-B2 (DQ869676), AetNAM-D2 (DQ869677), HvNAM-2 (DQ869679), TtNAM-A1 (DQ869672), AetNAM-D1 (DQ869675), TtNAM-B1 (DQ869673), NAM-G (AEI98797)
$N A M-V 1$. It has been shown that NAM-A1, B1, B2, D1, and $D 2$ all function in the regulation of grain protein content, iron, and zinc. Therefore, it is reasonable to speculate that the intact $N A M-V 1$ gene might encode a protein with a similar function. There were three proteins in group II; all three are from Arabidopsis. Among these AtNAC2 is associated with lateral root development [20]. Group III included three proteins. In this group, OsABA91266 and OsABA95705 come from Oryza sativa. TaNAC69 come from wheat, which responses to cold, drought and salt stress, and being associated with the adaptability of wheat under stress conditions [21]. Group IV also included three genes, that was TaNAC2 of wheat, OsN_NP 912423 of Oryza sativa and AtNAC3 of Arabidopsis. Both TaNAC2 and OsN_NP 912423 were related to stress tolerance $[22,23]$.

\section{Sequence alignment and molecular maker development} In order to develop specific markers for the detection of the $N A M-V 1$ gene and other NAM genes in hexaploid common wheat, a multiple sequence alignment was conducted (Fig. 3, Additional file 1: Figure S1). Multiple sequence alignment of $N A M-A 1, B 1, B 2, D 1, D 2$, and $V 1$ showed that there was a specific "ATGTC" insert at the 247th nucleotide of NAM-V1. The "G to T" single nucleotide polymorphism (SNP) was only observed in the NAM$V 1$ gene at 785 th nucleotide (Fig. 3a). These polymorphic sites were introduced into the $3^{\prime}$ region of the forward and reverse primers, allowing us to develop a specific molecular marker, "CauNAM-V1", for the NAM-V1 gene.

We also found a region rich in polymorphism from the 240th -430th nucleotide of the NAM genes; this region contained six obvious polymorphic sites (Fig. 3b). A pair of primers, "CauNAM-ABD", for the simultaneous detection and discrimination among all of these NAM genes, was designed according to the sequence alignment results. For $N A M-A 1, B 1, B 2, D 1, D 2$, and $V 1$, the 

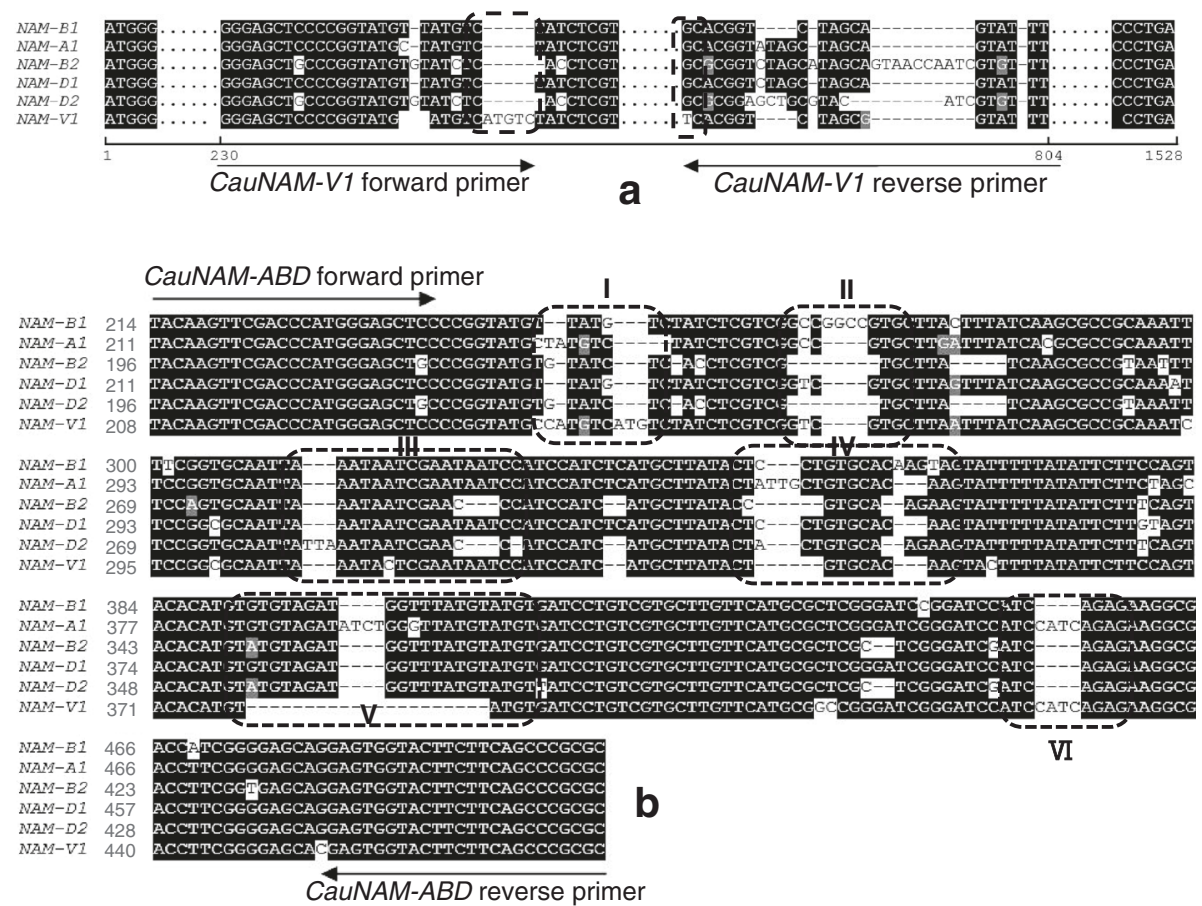

Fig. 3 DNA alignment and design of specific molecular markers. a Specific molecular marker for the detection of CauNAM-V1. b Polymorphic sites and specific molecular marker CauNAM-ABD for distinguishing among NAM-A1, NAM-B1, NAM-B2, NAM-D1, NAM-D2, and NAM-V1

expected lengths of the amplification products were $294 \mathrm{bp}, 290 \mathrm{bp}, 265 \mathrm{bp}, 283 \mathrm{bp}, 270 \mathrm{bp}$ and $270 \mathrm{bp}$, respectively.

\section{Molecular marker CauNAM-V1 is specific for the NAM-V1 gene and is linked with powdery mildew resistance gene Pm21}

To test if the molecular marker CauNAM-V1 was specific for the $N A M-V 1$ gene, it was used with DNA from common wheat Chinese Spring (CS), Aegilops tauschii, T. urartu, T. mononcoccum, Chinese Spring nullisomic-tetrasomic lines CS N2B-T2D and CS N6A-T6B, susceptible and resistance individuals from F2 a segregation population of $P m 21$, and a wheat cultivar carrying Pm12. CauNAM-V1 was able to amplify a product only in the materials carrying $P m 21$ that contained the 6VS chromosome of H. villosa (Fig. 4a). According to the powdery mildew resistance identification results (Fig. 4b), ten resistant individuals and ten susceptible individuals were used for amplification via CauNAM-V1. Using CauNAM-V1, a product was amplified from all of the tested resistant individuals; no product was amplified from any of the tested susceptible individuals (Fig. 4c). Thus the marker CauNAM-V1 is linked to Pm21. These experiments also indicate that $N A M-V 1$ comes from chromosome $6 \mathrm{~V}$, not from $6 \mathrm{~A}$ or $6 \mathrm{D}$.
Detection of NAM-A1, B1, D1, D2, and B2 using CauNAM$A B D$

Using CauNAM-ABD, five specific products with different sizes were amplified from common wheat Chinese Spring (CS); these products represented NAM-A1 (294 bp), B1 (290 bp), D1 (283 bp), D2 (270 bp) and B2 (265 bp), respectively (Fig. 5). For $P m 21$ and $P m 12$, there were no bands for $N A M-A 1$ or $N A M-B 1$, owing to the deletion of $6 \mathrm{AS}$ and $6 \mathrm{BS}$, respectively. Only one specific amplification band could be detected with T. moncoccum ( $\mathrm{A}^{\mathrm{m}}$ genome). In the Chinese Spring nullisomic-tetrasomic lines CS N6A-T6B, the band representing the $N A M-A 1$ product were not be observed. The band for the $N A M-B 1$ product was brighter than the other bands because there are two copies of the NAM-B1 gene in CS N6A-T6B. The same phenomenon was also observed in CS N2B-T2D, suggesting the Cau$N A M-A B D$ can also measure the copy number of $N A M$ genes. Thus, CauNAM-ABD can amplify and distinguish $N A M-A 1, N A M-B 1, N A M-B 2, N A M-D 1$, and NAM-D2 in hexaploid common wheat.

\section{Correlation analysis of GPC and genotype}

In order to analyze the contribution of NAM-V1 and NAM$A 1$ to GPC, four Pm21 F2 segregation populations (W50200, W50175, W50156, and W50176) were constructed. The average GPC for the NAM-V1/NAM-A1 genotypes in W50200, W50175, W50156, and W50176 were $13.94 \% / 13.42 \%, 17.99 \% / 16.88 \%, 13.33 \% / 13.31 \%$ 

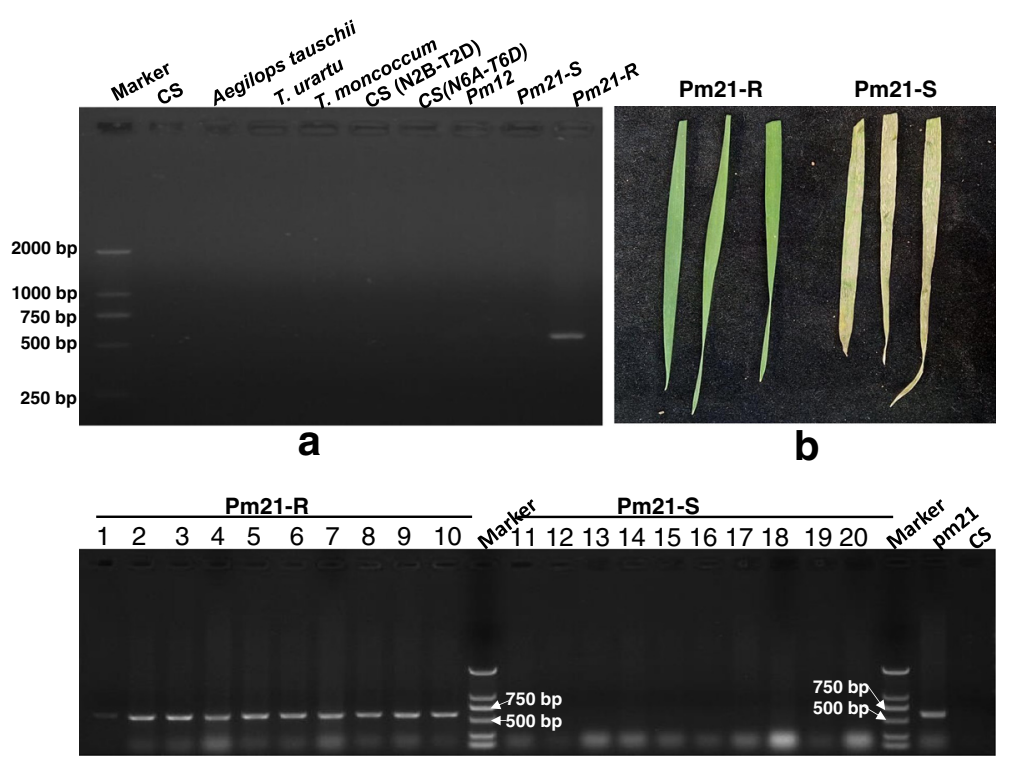

\section{C}

Fig. 4 Specific molecular marker for the NAM-V1 gene. a PCR amplification of the NAM-V1 gene using a specific molecular marker in different wheat materials. $\mathbf{b}$ Identification of the resistance of Pm21 segregation population to powdery mildew, $\mathbf{c}$ PCR detection using the CauNAM-V1 specific molecular marker in the segregation population resistant to powdery mildew

and $15.41 \% / 14.33 \%$, respectively (Fig. 6). The GPC of the individuals containing the $N A M-V 1$ gene were higher than those containing the $N A M-A 1$ gene in all four of the segregation populations. The average increasing of GPC were $0.52 \%, 1.11 \%, 0.02 \%$ and $1.08 \%$ in four populations. These results suggest that $N A M-V 1$ contributes to increasing GPCin6AL/6VStranslocation lines of hexaploid wheat.

\section{Discussion}

In developing countries, malnutrition caused by the lack of one or many kinds of trace elements is affecting more than 20 million people. In some areas, as many as $47 \%$ of preschool children suffer from iron deficiency, resulting in poor physical and mental development. Malnutrition caused by zinc deficiency affects about 10 million people worldwide. Zinc deficiency can also cause retarded growth and can destroy the body's immune system [24]. The $N A M-B 1$ gene from wild emmer wheat and the $N A M-A 1$, $N A M-D 1, N A M-B 2$, and $N A M-D 2$ genes from durum wheat not only affect the protein content of wheat grain, the expression levels of these genes are also positively correlated with the iron and zinc levels in grain [7]. In this

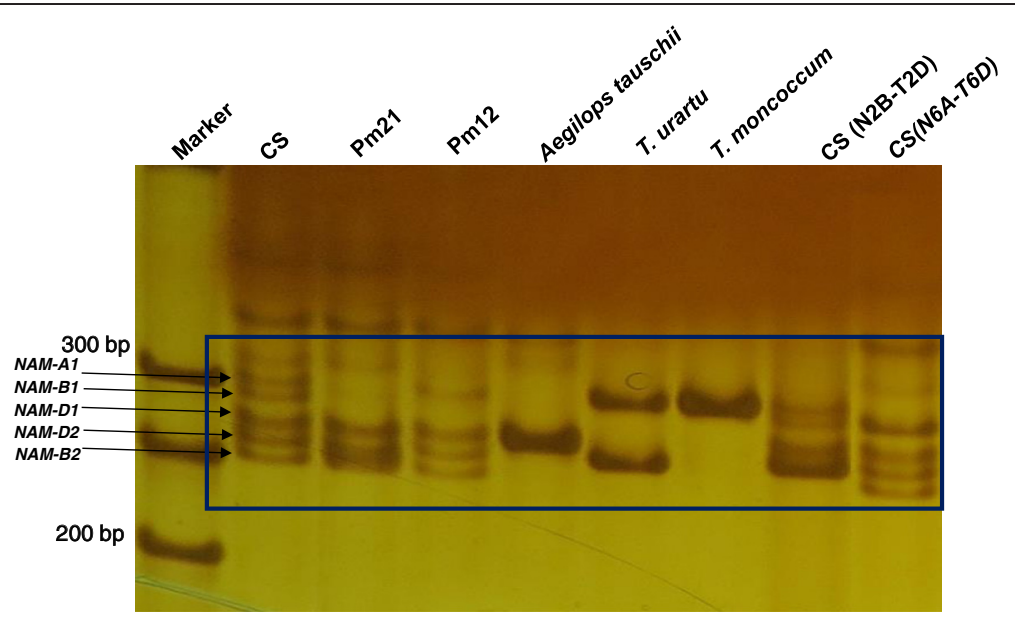

Fig. 5 The amplification of primer CauNAM-ABD in different species. Line 1 to line 9 represented Chinese Spring (CS), 6AL/6VS translocation of wheat carrying powdery mildew resistant gene Pm21. 6BL/6SS translocation of wheat carrying powdery mildew resistant gene Pm12, Aegilops tauschii, T. urartu, T. moncoccum, CS (N2B-T2D) and CS (N6A-T6D), respectively 


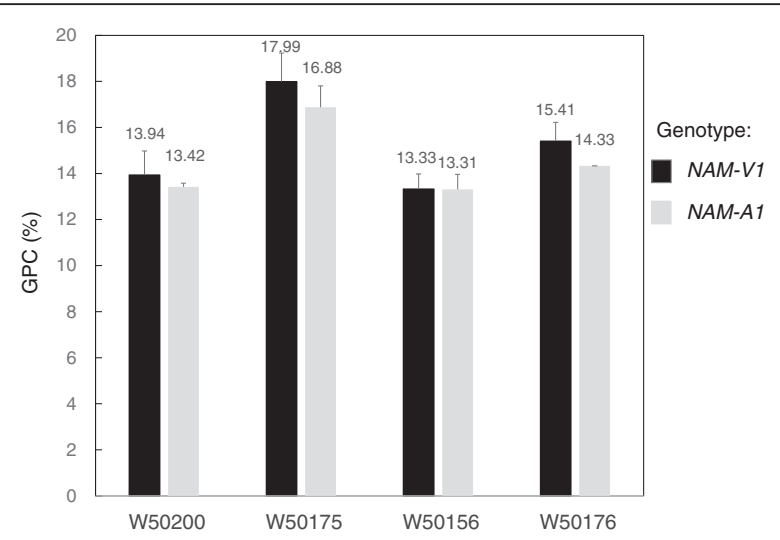

Fig. 6 Measurement of grain protein concentration (GPC) of four Pm21 segregation populations. Four Pm21 segregation populations (W50200, W50175, W50156, and W50176) were constructed. Genotypes were determined using the molecular marker CauNAM-V1. The GPC was measured by NIRS. Three replications were analyzed for each accession

study, a new homologous gene of $N A M-B 1, N A M-V 1$, was cloned from $H$. villosa. Gene structure analysis showed that the gene had a complete open reading frame, suggesting that $N A M-V 1$ is a functional gene.

Molecular marker-assisted selection plays an important role in current crop breeding methods, especially in plant disease-resistance breeding. To date, about 70 powdery mildew resistance genes have been identified. One of these is $P m 21$, an effective disease resistance gene for most of the physiological races of the fungal pathogen Blumeria graminis f. sp. Tritici [17]. Pm21 and NAM-V1 were all identified from 6VS of $H$. villosa. Because chromosome synapsis did not occur between 6AS of $H$. villosa and 6AS of common wheat during meiosis [25], the specific marker CauNAM-V1 can be used to detect Pm21 and loci on 6VS that may be associated with other agronomic traits such as the k-type sulfur-rich prolamins gene Gli-V2. Previous studies have shown that NAM-A1, NAM-B1, NAM-B2, $N A M-D 1$, and $N A M-D 2$ are all functional genes that are highly conserved in hexaploid common wheat [7]. Additionally, owing to sequence similarity, it has been difficult to discriminate the genotype of NAM genes. Here, we developed a molecular marker that can simultaneously amplify NAM-A1, NAM-B1, NAM-B2, NAM-D1, and $N A M-D 2$. The genotype and gene copy numbers can be estimated according the electrophoresis results, providing a useful method for screening high grain protein, zinc, and iron content wheat varieties.

Pm21 is one of the most effective resistance genes against powdery mildew. The 6AL/6VS translocation lines of hexaploid wheat, which carry $P m 21$, has been widely applied in wheat breeding programs. However, it is unclear whether the changes in GPC that occur following the introgression of chromosome segments of $H$. villosa, when original function gene $N A M-A 1$ in $6 \mathrm{~A}$ chromosome was removed. Here, we isolated the NAM-V1 gene from $H$. villosa and showed that NAM-V1 is an intact and likely functional gene in $6 \mathrm{AL} / 6 \mathrm{VS}$ translocation lines of hexaploid wheat. In common wheat, $N A M-A 1$ is known to be a functional gene. Our results demonstrate that the replacement of $N A M-A 1$ by $N A M-V 1$ confers increased grain protein content, implying that $N A M-V 1$ is more efficient than $N A M-A 1$ in increasing the GPC. The differences in the efficiency between $N A M-V 1$ and $N A M-A 1$ might be affected by many factors such as gene structure, gene expression levels, and/or promoter sequences. In addition, this study showed that the powdery mildew resistant genes Pm21 and NAM-V1 are responsible for co-segregating traits in wheat 6AL/6VS translocation lines. Therefore, the specific marker CauNAM-V1 can also be used for selecting both disease resistance and high GPC genotypes in wheat breeding programs. CauNAM-V1 is a dominant molecular marker that can be easily detected by agarose gel electrophoresis. CauNAM-V1 should help efforts to utilize disease resistance and high protein genes from 6VS of $H$. villosa in wheat improvement programs.

\section{Conclusions}

Here, we report the isolation of the NAM-V1 gene of $H$. villosa. This gene contributes to increasing GPC in 6AL/ 6VS translocation wheat lines. We developed a molecular marker for the specific detection of NAM-V1 and a molecular marker that can be used to simultaneously distinguished among the NAM-A1, NAM-B1, NAM-B2, $N A M-D 1$, and $N A M-D 2$ genes in a single step.

\section{Methods}

Plant material and fungal isolates

The einkorn wheat cultivars T. urartu $\left(\mathrm{A}^{\mathrm{u}}\right)$ and T. mononcoccum $\left(\mathrm{A}^{\mathrm{m}}\right)$ were obtained from the Plant Germplasm Institute of Kyoto University (Japan). Powdery mildew isolate E09 was provided by Prof. Xiayu Duan of the Institute of Plant Protection of the Chinese Academy of Agricultural Sciences. The wheat lines 2 N1862 (containing the powdery mildew resistance gene Pm12) and W50200 (containing the powdery mildew resistance gene $P m 21$ ), as well as the common wheat cultivars Chinese Spring and Xuezao are kept at our laboratory. Two Chinese Spring nullisome-tetrasomic lines for homeologous group 2 (CS N2B-T2B) and homeologous group 6 (CS N6A-T6B) were kindly provided by Drs. W. J. Raupp and B. S. Gill of the Wheat Genetics Resource Centre of Kansas State University, USA.

\section{Powdery mildew resistance identification}

Powdery mildew resistance identification was performed as described in a previous study [26]. The reaction of seedlings to powdery mildew were scored on 0 (no visible symptoms), 0; (necrotic flecks), 1 (necrosis with low sporulation), 
Table 1 Primers used in this study

\begin{tabular}{|c|c|c|c|c|}
\hline Primer name & Primer sequence $\left(5^{\prime}-3{ }^{\prime}\right)$ & Product length & Annealing Temperature & Purpose \\
\hline \multirow[t]{2}{*}{ NAMORF1 } & F: GATGAGGTCCATGGGCAG & $1528 \mathrm{bp}$ & $60^{\circ} \mathrm{C}$ & Genomic DNA cloning \\
\hline & R: TCATTTGCTCAGGGATTCC & & & \\
\hline \multirow[t]{2}{*}{ NAMORF2 } & F: ATGGGCAGCTCCGACTCA & $1540 \mathrm{bp}$ & $60^{\circ} \mathrm{C}$ & cDNA cloning \\
\hline & R: TCAGGGATTCCAGTTCACG & & & \\
\hline \multirow[t]{2}{*}{ CaUNAM-V1 } & F: TCCCCGGTATGCCATGTC & $575 \mathrm{bp}$ & $58^{\circ} \mathrm{C}$ & Specific molecular marker for NAM-V1 \\
\hline & R: AAGATACCGCTAGACCGTGA & & & \\
\hline \multirow[t]{2}{*}{ CaUNAM-ABD } & F: TACAAGTTCGACCCATGGGA & $265-294$ bp & $58^{\circ} \mathrm{C}$ & Molecular marker for $N A M-A 1, B 1, D 1, B 2$ and $D 2$ \\
\hline & R: GCGCGGGCTGAAGAAGTA & & & \\
\hline
\end{tabular}

2 (necrosis with medium sporulation), 3 (no necrosis with medium to high sporulation) and 4 (highly susceptible reactions).

\section{GPC determination}

According to a method described in previous studies [27, 28 , the grain protein content (GPC) in mature seeds from the $P m 21$ segregation population was measured by nearinfrared reflectance spectroscopy (NIRS) on a Perten DA 7200 instrument (Perten Instruments, Sweden). Three replicates were analyzed for each accession.

\section{Preparation of template DNA}

Genomic DNA was extracted from leaves using a cetyl trimethylammonium bromide (CTAB) method [29]. Total RNA was isolated using RNAiso plus Reagent (Takara, Japan) according the manufacturer's instructions and purified using DNase I. Complementary DNA was synthesized using a PrimeScript 1st Strand cDNA kit (Takara, Japan).

\section{Primer design and PCR Amplification}

The DNA sequences of NAM-A1 (DQ869672), NAM-D1 (DQ869675), NAM-B1 (DQ869673), NAM-B2 (DQ869676), and NAM-D2 (DQ869677) were obtained from GenBank (http://www.ncbi.nlm.nih.gov/genbank). Primer pairs were designed according to the DNA sequences of $N A M$ genes for genomic DNA cloning (NAMORF1) and cDNA cloning (NAMORF2). The forward and reverse primers contained the initiation codon and termination codon, respectively (Table 1). PCR reactions were performed as follows: $94{ }^{\circ} \mathrm{C}$ for $3 \mathrm{~min}$, followed by 35 cycles at $94{ }^{\circ} \mathrm{C}$ for $30 \mathrm{~s}, 58-60{ }^{\circ} \mathrm{C}$ for $30 \mathrm{~s}$, and $72{ }^{\circ} \mathrm{C}$ for $2 \mathrm{~min}$, with a final extension at $72{ }^{\circ} \mathrm{C}$ for $7 \mathrm{~min}$. The PCR products were separated on $1.0 \%$ agarose gels and photographed under UV light. After electrophoresis, the specific band was excised from the gel and ligated into pMD18-T vector for transformation. For the detection of molecular marker NAM-ABD, the PCR products were separated on $8 \%$ non-denaturing polyacrylamide gels. Gels were fast silver stained and photographed. The positive clones for sequence determination were screened by PCR using M13 primers.

\section{Bioinformatics analysis of the NAM-V1 gene}

The open reading frame (ORF) of the NAM-V1 gene was predicted using the NCBI online ORF Finder (http: //www.ncbi.nlm.nih.gov/gorf/gorf.html). The molecular weight and isoelectric point were predicted using DNAstar software (http://www.dnastar.com). The conserved domain (s) were predicted by alignment with NCBI CDD database (http://www.ncbi.nlm.nih.gov/cdd). Multiple sequence alignments were analyzed using ClustalW software (http://www. ch.embnet.org/software/ClustalW.html). Multiple-alignment files were shaded using BOXSHADE 3.2 (http://www. ch.embnet.org/software/BOX_form.html). Phylogenetic analysis conducted with MEGA 6 (www.megasoftware.net/).

\section{Additional file}

Additional file 1: Figure S1. Multiple alignments of deduced amino acid sequences of the NAM proteins. (RTF $117 \mathrm{~kb}$ )

Abbreviations

$6 \mathrm{AS}$, short arm of chromosome $6 \mathrm{~A} ; 6 \mathrm{BS}$, short arm of chromosome $6 \mathrm{~B} ; \mathrm{CS}$, common wheat cultivar Chinese Spring; GPC, grain protein content; NAM, no apical meristem; QTL, quantitative trait locus; SNP, single nucleotide polymorphism

\section{Acknowledgments}

The paper has been examined in detail by Dr. John Hugh Snyder.

Funding

This work was financially supported by the Natural Science Foundation of China (31271708, 31271710), the Ministry of Science and Technology (MOST) of China Program (2011YQ08005206), and the Young Talents Training Program of the Shandong Academy of Agricultural Sciences.

\section{Availability of supporting data}

The genomic and CDNA sequences of the NAM-V1 gene discussed in this manuscript have been deposited in NCBI's GenBank and are accessible with the accession number KR873101.

\section{Authors' contributions}

CX and $\mathrm{QS}$ designed the study. CZ, XL, YL, FL, MG, YM, XW, and ZN carried out most of the experiments and data analysis, and wrote the Materials and Methods section of the manuscript. CX and CZ wrote the manuscript, generated the figures, and finalized the table. All authors have read and approved the manuscript.

Competing interests

The authors declare that they have no competing interests. 


\section{Consent to publish}

Not applicable.

\section{Ethics and consent to participate}

Not applicable.

\section{Author details}

${ }^{1}$ Key Laboratory of Crop Heterosis and Utilization (MOE) and State Key Laboratory for Agrobiotechnology, Key Laboratory of Crop Genomics and Genetic Improvement (MOA), Beijing Key Laboratory of Crop Genetic Improvement, National Plant Gene Research Centre (Beijing), Department of Plant Genetics \& Breeding, China Agricultural University, Beijing 100193, China. 2Bio-Tech Research Center, Shandong Academy of Agricultural Sciences, Ji'nan 250100, China

Received: 18 November 2015 Accepted: 7 June 2016

Published online: 14 June 2016

\section{References}

1. Distelfeld A, Korol A, Dubcovsky J, Uauy C, Blake T, Fahima T. Colinearity between the barley grain protein content (GPC) QTL on chromosome arm $6 \mathrm{HS}$ and the wheat Gpc-B1 region. Mol Breeding. 2008;22(1):25-38.

2. Groos C, Robert N, Bervas E, Charmet G. Genetic analysis of grain protein-content, grain yield and thousand-kernel weight in bread wheat. Theor Appl Genet. 2003; 106(6):1032-40

3. Prasad M, Kumar N, Kulwal PL, Roder MS, Balyan HS, Dhaliwal HS, Gupta PK. QTL analysis for grain protein content using SSR markers and validation studies using NILs in bread wheat. Theor Appl Genet. 2003;106(4):659-67.

4. Cantrell RG, Joppa LR. Genetic analysis of quantitative traits in wild emmer (Triticum turgidum L. var. dicoccoides). Crop Sci. 1991;31(3):645-9.

5. Joppa LR, Du C, Hart GE, Hareland GA. Mapping gene (s) for grain protein in tetraploid wheat (Triticum turgidum L.) using a population of recombinant inbred chromosome lines. Crop Sci. 1997;37(5):1586-9.

6. Olmos S, Distelfeld A, Chicaiza O, Schlatter AR, Fahima T, Echenique V, Dubcovsky J. Precise mapping of a locus affecting grain protein content in durum wheat. Theor Appl Genet. 2003:107(7):1243-51.

7. Uauy C, Distelfeld A, Fahima T, Blechl A, Dubcovsky J. A NAC Gene Regulating Senescence Improves Grain Protein, Zinc, and Iron Content in Wheat. Science. 2006;314(5803):1298-301.

8. Aida M, Ishida T, Fukaki H, Fujisawa H, Tasaka M. Genes involved in organ separation in Arabidopsis: an analysis of the cup-shaped cotyledon mutant. Plant Cell. 1997;9(6):841-57.

9. Souer E, Van Houwelingen A, Kloos D, Mol J, Koes R. The no apical meristem gene of Petunia is required for pattern formation in embryos and flowers and is expressed at meristem and primordia boundaries. Cell. 1996; 85(2):159-70.

10. Fang Y, You J, Xie K, Xie W, Xiong L. Systematic sequence analysis and identification of tissue-specific or stress-responsive genes of NAC transcription factor family in rice. Mol Genet Genomics. 2008;280(6):547-63.

11. Olsen AN, Ernst HA, Leggio LL, Skriver K. NAC transcription factors: structurally distinct, functionally diverse. Trends Plant Sci. 2005;10(2):79-87.

12. Riechmann JL, Heard J, Martin G, Reuber L, Jiang C, Keddie J, Adam L, Pineda O, Ratcliffe OJ, Samaha RR. Arabidopsis transcription factors: genome-wide comparative analysis among eukaryotes. Science. 2000; 290(5499):2105-10.

13. Hu X, Wu B, Liu D, Wei Y, Gao S, Zheng Y. Variation and their relationship of NAM-G1 gene and grain protein content in Triticum timopheevii Zhuk. J Plant Physiol. 2013;170(3):330-7.

14. Jamar C, Loffet F, Frettinger P, Ramsay L, Fauconnier M, Du Jardin P. NAM1gene polymorphism and grain protein content in Hordeum. J Plant Physiol. 2010;167(6):497-501.

15. Sears ER. Addition of the genome of Haynaldia villosa to Triticum aestivum. Am J Bot. 1953:168-174.

16. Grądzielewska A. The genus Dasypyrum--part 1. The taxonomy and relationships within Dasypyrum and with Triticeae species. Euphytica. 2006; 152(3):429-40

17. Cao A, Xing L, Wang X, Yang X, Wang W, Sun Y, Qian C, Ni J, Chen Y, Liu D. Serine/threonine kinase gene Stpk-V, a key member of powdery mildew resistance gene Pm21, confers powdery mildew resistance in wheat. Proc Natl Acad Sci. 2011;108(19):7727-32.
18. Blanco A, Resta P, Simeone R, Parmar S, Shewry PR, Sabelli P, Lafiandra D. Chromosomal location of seed storage protein genes in the genome ofDasypyrum villosum (L.) Candargy. Theor Appl Genet. 1991;82(3):358-62.

19. Ma J, Zhou $R$, Dong $Y$, Wang $L$, Wang $X$, Jia J. Molecular mapping and detection of the yellow rust resistance gene Yr26 in wheat transferred from Triticum turgidum L. using microsatellite markers. Euphytica. 2001;120(2):219-26.

20. He XJ, Mu RL, Cao WH, Zhang ZG, Zhang JS, Chen SY. AtNAC2, a transcription factor downstream of ethylene and auxin signaling pathways, is involved in salt stress response and lateral root development. Plant J. 2005;44(6):903-16.

21. Baloglu MC, Oz MT, Oktem HA, Yucel M. Expression analysis of TaNAC69-1 and TtNAMB-2, wheat NAC family transcription factor genes under abiotic stress conditions in durum wheat (Triticum turgidum). Plant Mol Biol Rep. 2012;30(5):1246-52.

22. Mao X, Zhang H, Qian X, Li A, Zhao G, Jing R. TaNAC2, a NAC-type wheat transcription factor conferring enhanced multiple abiotic stress tolerances in Arabidopsis. J Exp Bot. 2012;63(8):2933-46.

23. Al-Abdallat AM, Ali-Sheikh-Omar MA, Alnemer LM. Overexpression of two ATNAC3-related genes improves drought and salt tolerance in tomato (Solanum lycopersicum L.). Plant Cell, Tissue and Organ Culture. 2015;120:9891001. doi:10.1007/s11240-014-0652-8

24. Cakmak I, Pfeiffer WH, McClafferty B. Review: Biofortification of durum wheat with zinc and iron. Cereal Chem. 2010;87(1):10-20.

25. Liu D, Qi L, Chen P, Zhou B, Zhang S. Precise identification of alien chromosome segment introduced in wheat and the stability of its resistance gene. Acta Genet Sin. 1995;23(1):18-23.

26. Liu Z, Sun Q, Ni Z, Yang T, Mclntosh RA. Development of SCAR markers linked to the Pm21 gene conferring resistance to powdery mildew in common wheat. Plant Breed. 1999;118(3):215-9.

27. Ma J, Zhang CY, Yan GJ, Liu CJ. Improving yield and quality traits of durum wheat by introgressing chromosome segments from hexaploid wheat. Genet Mol Res. 2013;12(4):6120-9.

28. Wang L, Cui F, Wang J, Jun L, Ding A, Zhao C, Li X, Feng D, Gao J, Wang H. Conditional QTL mapping of protein content in wheat with respect to grain yield and its components. J Genet. 2012;91(3):303-12.

29. Porebski S, Bailey LG, Baum BR. Modification of a CTAB DNA extraction protocol for plants containing high polysaccharide and polyphenol components. Plant Mol Biol Rep. 1997;15(1):8-15.

\section{Submit your next manuscript to BioMed Central and we will help you at every step:}

- We accept pre-submission inquiries

- Our selector tool helps you to find the most relevant journal

- We provide round the clock customer support

- Convenient online submission

- Thorough peer review

- Inclusion in PubMed and all major indexing services

- Maximum visibility for your research

Submit your manuscript at www.biomedcentral.com/submit
) Biomed Central 